\title{
CONVERSA: um cuidado fundamental de enfermagem na perspectiva do cliente hospitalizado
}

Luisa Maria da Silva de Barcelos* Neide Aparecida Titonelli Alvim**

\section{Resumo}

O estudo enfoca a conversa como cuidado integrador da enfermagem hospitalar. Teve como objetivo analisar a conversa como etapa essencial do diálogo entre cliente e a equipe de enfermagem. Participaram cinco pessoas já submetidas à internação hospitalar e que estavam sob acompanhamento ambulatorial em decorrência de viver com AIDS. As informações foram obtidas por meio da técnica de sensibilidade e criatividade 'Almanaque', entrevista semi-estruturada e observação participante. $\mathrm{O}$ estudo contribuiu para reforçar o caráter relacional do cuidado de enfermagem e a posição do cliente como sujeito deste cuidado, que expressa suas solicitações e reivindicações no processo dialógico entre este e a equipe, através da conversa, entendida como um cuidado expressivo da enfermagem. Descritores: enfermagem; cuidado de enfermagem; AIDS; diálogo

\begin{abstract}
The study focuses conversation as care that integrates other elements of hospital nursing. It had as its objective to analyze conversation as an essential stage of the dialogue between the patient and the nursing team. Five people participated who had already been hospitalized and that were now under clinical monitoring due to learning to live with AIDS. The information was obtained by means of the "Almanac" technique of sensitivity and creativity, semi-structured interview, and by active observation. The study contributed to reinforce the relational nature of the nursing care and the position of the patient as an object of this care who expresses his/her requests and wants in the process of dialoguing between this person and the nursing staff, expressed by conversation, which is viewed as a significant factor in nursing care.

Descriptors: Nursing; nursing care; AIDS; dialogue

Title: Conversation: a fundamental nursing care from the hospitalized patient's perspective
\end{abstract}

\section{Resumen}

El estudio enfoca la conversación como cuidado integrador de la enfermería hospitalaria. Tiene como objetivo analizar la conversación como etapa esencial del diálogo entre el cliente y el equipo de enfermería. Participaron cinco personas, que ya habían ingresado antes al hospital y -en el momento del estudio- estaban recibiendo cuidados en el ambulatorio, como consecuencia de haber contraído el SIDA. Las informaciones se obtuvieron por medio de la técnica de sensibilidad y creatividad "Almanaque", entrevista semi-estructurada y observación participante. El estudio ha contribuido para reforzar el carácter relacional del cuidado de enfermería y la posición del cliente como sujeto de este cuidado, quien expresa sus solicitaciones y reivindicaciones en el proceso dialógico entre él mismo y el equipo, mediante la charla, la conversación, entendida como un cuidado expresivo de enfermería.

Descriptores: Enfermería; cuidados de enfermería; HIVISIDA; diálogo

Título: Conversación: un cuidado fundamental de enfermería en la perspectiva del cliente hospitalizado

\section{Introdução}

Este estudo integra a linha de pesquisa "Prática dialógica no cuidado de enfermagem", que vem sendo desenvolvida pelo Núcleo de Pesquisa de Fundamentos do Cuidado de Enfermagem (NUCLEARTE), cujo enfoque é o diálogo como fundamental na relação do cuidado.

O objeto desta pesquisa foi a conversa como cuidado integrador da enfermagem hospitalar. Teve como objetivo analisar a conversa como etapa essencial do diálogo entre o cliente e a equipe de enfermagem, no espaço do cuidado. Foi discutida com base nos conceitos extraídos de Jean Watson ${ }^{(1)}$, segundo os quais a enfermagem é caracterizada como uma ciência do cuidado que orienta sua prática na abordagem humanista, tomando o cuidado como objeto desta prática. Isso sugere que o mesmo se estabelece na relação interpessoal cliente - sujeito do cuidado, e o profissional - agente da ação, ambos dotados de emoções e sentimentos inerentes à condição de seres humanos que se expressam intersubjetivamente em todo o processo de cuidar; logo, o cuidado é relacional e recíproco. Nesta direção, Watson ${ }^{(1)}$ classifica as atividades de enfermagem em instrumental e expressiva. A primeira refere-se ao atendimento das necessidades mais voltadas ao aspecto físico, biológico, do cliente, como a higiene corporal, a medicação e alguns procedimentos técnicos. Já nas atividades expressivas, se considera em primeiro plano os aspectos psico-sociais. Vale ressaltar que entendemos a conversa como um cuidado expressivo da enfermagem.

Em Freire ${ }^{(2,3)}$, buscamos respaldo para sustentar que a relação de cuidado deve se estabelecer horizontalmente, ou seja, recusamos o princípio da relação vertical cuja ação é carregada de uma prática e de um diálogo autoritário, "conhecer é tarefa de sujeitos, não de objetos"(2:27). E é somente como sujeito que o cliente pode realmente conhecer, questionar, criticar e transformar a realidade que se lhe apresenta. Nesse sentido, entendemos diálogo como palavra circunscrita em duas dimensões: ação e reflexão. Assim, "não há palavra verdadeira que não seja na práxis"(2:77). Logo, se e na práxis que a palavra se impõe, ela não é dita para os outros, mas com a palavra dos outros.

Vindo ao encontro das concepções deste autor, o cuidado humanizado, preconiza atitudes como habilidade e a sensibilidade na comunicação verbal e não verbal. Saber ouvir, o que e quando falar, compartilhar idéias e decisões, são ingredientes fundamentais para o estabelecimento horizontal de cuidado. Assim, o cuidado não pressupõe a individualidade, mas uma transação pessoa a pessoa, onde o enfermeiro não atua no cliente, mas com o cliente(1).

\footnotetext{
* Enfermeira aposentada do Ministério da Saúde. Mestranda da Escola de Enfermagem Anna Nery/Universidade Federal do Rio de Janeiro/Núcleo de Pesquisa de Fundamentos do Cuidado de Enfermagem (EEAN/UFRJ/NUCLEARTE). Professora da Universidade Estácio de Sá.

** Enfermeira. Professor Adjunto do Departamento de Enfermagem Fundamental da EEAN/UFRJ, membro da diretoria colegiada do NUCLEARTE, coordenadora de pesquisa da EEAN.

E-mail do autor: luisabarcelos@uol.com.br
} 


\section{Dados Metodológicos da Pesquisa}

Optamos pela pesquisa qualitativa por entendê-la adequada às questões que envolvem o relacionamento interpessoal, na medida em que conta com uma variedade de métodos e técnicas que possibilitam o desvendar dos problemas emergentes do cotidiano dessas relações.

Os sujeitos foram cinco clientes adultos, de ambos os sexos, vivendo com AIDS. Os critérios de inclusão na pesquisa foram ser clientes que já se submeteram à internação hospitalar em decorrência da doença e que estavam sob acompanhamento ambulatorial num hospital municipal do Rio de Janeiro. A opção pelos sujeitos se justifica pela nossa experiência profissional de vinte anos no âmbito hospitalar convivendo com clientes com AIDS.

Na produção de dados, trabalhamos com a triangulação de técnicas, conjugando a técnica de criatividade e sensibilidade "Almanaque", com a entrevista semi-estruturada e a observação participante. Vale destacar que, com o uso da criatividade e da sensibilidade na produção de dados da pesquisa, o imaginário transcendeu a racionalidade e a diversidade das experiências e vivências dos sujeitos emergiu da expressão criativa e sensível e serviu de motivadora para o diálogo entre nós, pesquisadoras, e os participantes do estudo. Durante toda a produção de dados, foram registradas as expressões verbais e não verbais dos sujeitos. Cada encontro durou, em média, de 30 a 60 minutos. Os dados foram analisados à luz da análise de discurso ${ }^{(4,5)}$.

Cabe ainda ressaltar que foram respeitados os aspectos éticos da pesquisa dispostos na Resolução 196/96, do Conselho Nacional de Saúde/MS, que regula as Normas de Pesquisa envolvendo Seres Humanos. Assim, além da autorização da Comissão de Ética em Pesquisa da Instituição, cenário do estudo, os participantes assinaram o termo de consentimento livre e esclarecido. Ainda em observância à mencionada Resolução, mantivemos o anonimato dos sujeitos por meio de nomes próprios fictícios por eles escolhidos, a saber: João, Maria, Pedro, Margui e Jorge.

\section{Resultados da Pesquisa}

Ao anunciar a posição que ocupavam no cuidado de enfermagem hospitalar e a maneira pela qual participavam deste, os sujeitos do estudo situaram a conversa como eixo integrador do cuidado. Ou seja, quando relataram suas experiências positivas de cuidado da enfermagem no contexto hospitalar, a conversa emergiu como um cuidado fundamental.

Vale lembrar que a conversa expressa por meio da palavra, é uma das etapas do diálogo, um canal importante de comunicação através da qual se pode promover a integração, a interação e o encorajamento para enfrentar as crises impostas, tanto pelo processo de internação, quanto pela doença em si. Ela inclui, entre outras coisas, a capacidade de não somente falar, mas de saber ouvir e de trocar informações; além da linguagem corporal acessível à comunicação, através do tom de voz, do toque, do olhar, da expressão facial e outras características essenciais no cuidado.

Em releitura dos escritos acerca da interação dialógica, se destaca que "o eu só existe a partir do diálogo com os outros eus. [...] posso ver o que o outro não pode ver e o outro vê o que não posso ver [...]"(6:319).

Nessa linha de pensamento, o outro é fundamental e indispensável em todo o processo dialógico, pois somente assim o homem, na relação com o outro, forma sua própria consciência e se constitui como sujeito. Através das palavras

${ }^{\mathrm{a} O}$ Almanaque consiste na expressão da subjetividade e da criatividade a partir da introspeção que o recorte e a colagem de gravuras de diversas naturezas proporcionam aos sujeitos da pesquisa. do outro, o homem se transforma dialogicamente. Para tanto, não se trata da palavra morta, mas, da palavra viva(2).

Reportando esse movimento de construção do sujeito dialógico para o espaço do cuidado de enfermagem hospitalar, reforçamos que ao observar essa interação dialógica, o aluno (cliente) não é mais um agente passivo e receptivo, mas um sujeito que age e, pelo seu discurso, se faz ouvir, recriando-se no seio de outras vozes. A ação compartilhada, permeando o espaço pedagógico, humaniza o processo educacional(6).

Nesse sentido, a fala de 'João' é elucidativa. Quando questionado sobre o tipo de participação que manteve durante o cuidado de enfermagem hospitalar, ele relatou: [...] Elas me ouviam, me deixavam falar, pediam para eu orar a Jesus [...] Muito bom! [...].

Deste modo, pensamos que a equipe de enfermagem precisa exercitar a sensibilidade na interação com o cliente. Para nós, esse exercício advém do diálogo, do respeito às diferenças entre nós e os clientes, da disponibilidade em deixar desvelar aquilo que não sabemos ou pouco sabemos, ao tempo em que nos abrimos para saber melhor o que acreditamos que já sabemos e conhecermos do outro aquilo que possamos fechar o caminho a conhecer. Portanto, "o sujeito que se abre ao mundo e aos outros inaugura com seu gesto a relação dialógica em que se confirma como inquietação e curiosidade, como inconclusão em permanente movimento na História"(2:154) Vejamos a enunciação dialógica a seguir:

[...] Eu conversava muito com elas (a equipe de enfermagem), depois que comecei a aceitar minha doença [...]. (João)

O que você pensa sobre o diálogo entre você e a enfermagem? (Pesquisadoras)

Importante. Desejo que a enfermagem continue assim [...] Maravilhosa! Prestando a solidariedade a todos que se internam num hospital. (João)

Seguindo esse raciocínio, pensamos que, na relação dialógica entre a equipe de enfermagem e o cliente vivendo com AIDS, o processo educativo pode ser terapêutico, pois favorece um relacionamento de reciprocidade através da comunicação. Desta forma, acredito ser possível minimizar as sensações de medo e angústia manifestadas entre a equipe de enfermagem e o cliente e assim favorecer o processo de aceitação na reabilitação e tratamento da doença, atendendo não somente às suas necessidades humanas básicas, do ponto de vista biológico, mas mantendo a visão holística do ser humano e o cuidado a ele prestado.

Reforçando a importância da conversa no cuidado, o discurso de 'Maria' complementa o de 'João':

[...] Fiquei internada um mês e três dias, sem andar, sem mexer os braços, mas arranjei uma amigona, a Enfermeira M. Ela fazia tudo para mim [...] Ela gostava de mim, tinha paciência e a gente conversava muito. Conversar é bom, quando alguém escuta a gente. Ela me escutava, rezava comigo... Conversar é muito bom [...]. (Maria)

Assim, "cuidado em sentido amplo, é uma forma de expressão, de relacionamento com o outro ser e com o mundo, enfim, como forma de viver plenamente"(1:17). Como é notório, a AIDS proporciona tanto um desequilíbrio no cliente, família e coletividade, quanto um sentimento de medo e insegurança na equipe de enfermagem. E para cuidar de tão complexo ser, que ora chora pela dor de ir (morte), e ora chora pela dor do vir (vida), o profissional precisa desenvolver a habilidade da escuta sensível no processo dialógico.

[...] não é falando aos outros, de cima para baixo, sobretudo, como se fôssemos os portadores da verdade a ser transmitida aos demais, que aprendemos a escutar, mas é escutando que aprendemos a falar com eles. Somente quem escuta paciente e criticamente o outro, 
fala com ele, mesmo que, em certas condições, precise de falar a ele $\mathrm{e}^{(3: 128)}$.

Nessa perspectiva, entendemos que a maneira pela qual o cuidado é prestado contribui para uma ação terapêutica das mais eficazes, capaz de não só curar o corpo, mas de trazer também o conforto ao espírito. O cuidado que traz no seu contexto a objetividade da técnica e a subjetividade da criação incentiva à equipe de enfermagem a refletir e a olhar de forma genuína a vida, melhorando a qualidade para aqueles que física ou emocionalmente dependem dela. É no cotidiano do cuidar que a relação dialógica enfermagem - cliente pode resultar em apoio, equilíbrio e bem-estar.

É necessário considerar, contudo, a posição do sujeito no diálogo. 'Maria', por exemplo, é uma cliente que aparentou nervosismo, irritação, apesar da mãe estar sempre junto, como permaneceu durante todo o nosso encontro na produção de dados. Segundo relatou, a dependência foi criada a partir do comprometimento físico advindo da doença. 'Maria' precisa de ajuda para andar, comer, banhar-se... Esta sua condição a faz manter-se sempre acuada, associado, evidentemente, ao fato de viver isolada socialmente. Durante nosso encontro, demonstrou um grande receio de submeter-se à nova internação e não encontrar o único referencial de experiência positiva no cuidado de enfermagem hospitalar, ou seja, a auxiliar de enfermagem.

Isso nos faz refletir sobre o fato de que, ao tempo em que a conversa demonstra uma faceta importante do cuidado expressivo, por outro lado, há de considerar no discurso de 'Maria', uma relação de dependência que pode prejudicar a sua autonomia. Salientamos que:

O grande perigo do assistencialismo está na violência do seu antidiálogo, que, impondo ao homem mutismo e passividade, não the oferece condições especiais para o desenvolvimento ou a 'abertura' de usar a consciência que, nas democracias autênticas, há de ser cada vez mais crítica [...]. Daí as relações do assistencialismo com a massificação, de que é a um tempo efeito e causa[... $]^{(7: 57)}$.

Sob este prisma, a conversa não seria uma qualidade positiva do cuidado em que pese a sua capacidade integradora. Por outro lado, não podemos deixar de considerar que a conversa, enquanto exercício dialógico entre o cliente e a equipe de enfermagem, facilita a interação e a negociação do cuidado, conforme ilustra a fala a seguir: [...] Seria muito bom se todos conversassem, porque aí a gente podia dizer: 'faz depois', 'esquenta a água do banho', 'está doendo', 'estou com sono' [...]. (Maria)

O discurso de 'Maria' revela várias solicitações de cuidado que no plano dialógico entre a equipe de enfermagem e o cliente, podem ser negociadas sem prejuízos para ambos; ao contrário, os ganhos no processo de cuidar podem ser imensuráveis.

Vale destacar que o espaço intersubjetivo do cuidado permite a comunicação entre os envolvidos na relação. Ele deve servir não somente para o cumprimento de um procedimento técnico, mas como um ambiente de participação, de interação, em que clientes e equipe de enfermagem envolvidos possam dialogar, trocar experiências, fazer reivindicações, expressarem, enfim, seus desejos e necessidades. Afinal, "o encontro entre quem cuida e quem é cuidado se estabelece no cuidar e é permeado pela objetividade técnica do cuidado, pelo conhecimento e pela subjetividade dos sujeitos envolvidos na relação"(8:189).

Neste contexto, ressaltamos que a equipe de enfermagem, quando realiza um cuidado meramente técnico, deixa de valorizar os aspectos subjetivos que perpassam o cuidar, como o zelo, o carinho, a paciência, a preocupação... Não obstante, vale lembrar que o foco de atenção do cuidado de enfermagem é o cliente, sujeito partícipe deste cuidado, com o qual precisamos interagir, sensivelmente, para prestar os cuidados técnicos necessários. Nessa direção, é mister referir que um dos pressupostos da teoria de enfermagem de Watson $^{(1)}$ destaca a interação pessoal como indispensável ao cuidado. E a conversa empática permite a compreensão das necessidades e desejos dos clientes, através da palavra enquanto signo dialógico.

Nesse sentido,

A partir da intersubjetividade originária poderíamos dizer que a palavra, mais do que instrumento é origem da comunicação - a palavra é essencialmente diálogo. A palavra abre a consciência para o mundo comum das consciências, em diálogo, portanto. [...] A palavra, porque lugar de encontro e do reconhecimento das consciências, também o é do reencontro e reconhecimento de si mesmo(2:19)

Nessa linha de raciocínio, nos colocamos diante da palavra criadora de consciência, não aquela repetida, alienante, pois essa é

"monólogo das consciências que perderam sua identidade, isoladas, imersas na multidão anônima e submissas a um destino que lhes é imposto e que não são capazes de superar, com a decisão de um projeto"(2:19).

A palavra que vem ao encontro de nossa concepção neste estudo, é a 'palavra viva e dinâmica'. Esta sim é dialógica e transformadora, na medida em que reconhece o outro e a si mesmo, no outro. "Não há consciências vazias; por isto os homens não se humanizam, senão humanizando o mundo"(2:20).

Neste contexto, é preciso que haja a superação da opressão, que só é possível na medida em que opressores e oprimidos se reconheçam como sujeitos no mundo. Como ressaltamos "a conquista implícita no diálogo é a do mundo pelos sujeitos dialógicos, não a de um pelo outro"(2:79). Mas é necessário que os cuidadores reconheçam nos clientes sua capacidade criadora que, na condição de sujeitos, exercitam a dialogicidade. Nesse sentido, é bom que se reflita sobre

[...] Como posso dialogar, se alieno a ignorância, isto é, se a vejo sempre no centro, nunca em mim? Como posso dialogar, se me admito como um homem diferente, virtuoso por herança, diante dos outros, meros isto', em quem não reconheço outros eu? Como posso dialogar, se me sinto participante de um gueto de homens puros, donos da verdade e do saber, para quem todos os que estão fora são 'essa gente', ou são 'nativos inferiores'?[...] $]^{(2: 80)}$

Pensamos que no cenário do cuidado de enfermagem hospitalar baseado no diálogo, entendido como uma das ferramentas do cuidado humano, todos os sentimentos que afloram na/da relação cliente-equipe de enfermagem, são redimensionados, pois o ato da comunicação e a interação com o outro, são capazes de gerar, por um lado, novas possibilidades de enfrentamento da doença pelo cliente; e, por outro, da difícil tarefa da equipe de enfermagem cuidar com sensibilidade, ou seja, com afeto, compaixão, responsabilidade, cumplicidade... Instrumentos importantes do cuidado humano.

Quando falamos da tarefa de cuidar, sensivelmente, como uma atividade difícil, reportamos-nos à nossa vivência profissional trabalhando com clientes vivendo com AIDS no ambiente hospitalar. O que observávamos é que o sofrimento entre a vida e a morte do cliente, associado às contingências do dia-a-dia hospitalar, provocavam múltiplos sentimentos e reações em ambos - clientes e equipe de enfermagem. Esta, por sua vez, tentava manter o equilíbrio emocional frente à realidade posta. O convívio com o doente vivendo com AIDS, assim como ocorre na interação com alguns outros casos de doentes crônicos, deixam marcas profundas na equipe de enfermagem. Vale salientar que, o fato de a equipe estar "instrumentalizada" para o ato de cuidar, não lhe garante o preparo necessário para lidar com as diferentes dimensões 
que envolvem o cuidado.

Isto porque, entendemos que a mera aquisição do saber técnico não é suficiente para engendrar atitudes e ações que dêem conta da multiplicidade de fatores que envolvem o cuidado humano. Assim, "[...] o cuidar passou de um comportamento de apenas sobreviver a ações, e hoje é considerado uma forma de ser, de se relacionar e constituir a essência da enfermagem $[\ldots]^{\prime \prime(9: 75)}$.

Neste novo milênio, observamos um cenário voltado para uma preocupação crescente em dar lugar a novos paradigmas aplicados à saúde que considerem e valorizem o ser humano em sua totalidade, os quais têm reflexos diretos no processo de cuidar da enfermagem. De modo que "[...] Se nos interessa analisar o compromisso do profissional com a sociedade, teremos que reconhecer que ele, antes de ser profissional, é homem. Deve ser comprometido por si mesmo [...]"(2:19). Nessa perspectiva, vale salientar que, a equipe de enfermagem possui valores sociais, culturais, conhecimentos e atitudes; pensar a pessoa a partir de tais considerações é considerar a influência desta trajetória no contexto da ação do cuidado.

O diálogo é o encontro amoroso dos homens que mediatizados pelo mundo, o 'pronunciam', isto é, o transformam, e, transformando-o, o humanizam para a humanização de todos $^{(2)}$. Nesse sentido, pensamos ser importante priorizar o diálogo na relação que se estabelece com o cliente no espaço do cuidado de enfermagem hospitalar, pois a comunicação favorece intencionalmente um contato horizontal capaz de não somente compreender as necessidades e desejos do cliente, mas na medida do possível, tornar o ambiente propício no atendimento dos mesmos.

Deste modo, é possível que o cliente possa minimizar sua angústia e sofrimento, através da dialogicidade.

Quando o homem compreende sua realidade, pode levantar hipótese sobre o desafio dessa realidade e procurar solução. Assim, pode transformá-la e com seu trabalho pode criar um mundo próprio: seu eu e suas circunstâncias ${ }^{(2: 30)}$

E é assim que 'Pedro' entendeu sua participação no cuidado de enfermagem, motivo pelo qual o qualificou como positivo: [...] nós conversávamos muito sobre o preparo, dia e hora da cirurgia [...].

Não obstante, é necessário salientar que o modelo pedagógico de transmissão de informações é vertical, monológico e não contribui para a consciência crítica do porquê fazer determinadas ações ou procedimentos, porque depositadas, armazenadas, e não apreendidas. Assim, cabe lembrar que, por um lado, o fato de o cliente verbalizar suas necessidades e desejos de cuidado, ou, por outro lado, a enfermeira falar acerca do procedimento que realiza, essa ação, por si só, não garante a transformação do espaço do cuidado em um ambiente de participação e dialogicidade. Para que na verdade assim seja considerado, faz-se necessária que a atitude de ambos conduza ao atendimento dos princípios que regem uma relação dialógica.

Também é oportuno ressaltar que a participação no cuidado, segundo o eixo teórico que norteia este estudo, implica integração. Logo, participar de cuidados de enfermagem numa instituição hospitalar, assim como em qualquer outro cenário de cuidar, requer, necessariamente, a interação dos sujeitos envolvidos que imprimem no espaço do cuidado as relações políticas, estéticas e éticas inerentes a qualquer relacionamento pessoa-pessoa. Isto quer dizer que o cliente deva ser capaz de posicionar-se criticamente no contexto do cuidado, sob pena de tornar-se inoperante, acomodado, reduzido a mero objeto do cuidado.

Portanto, entendemos que o cuidado de enfermagem deve possibilitar ao profissional o desenvolvimento de suas habilidades tanto sensíveis, quanto técnicas. Para cuidar do outro é importante aplicar o saber técnico que se dispõe, além do relacionamento interpessoal, sustentado na dialogicidade entre a equipe de enfermagem e o cliente.

É mister esclarecer que não negamos a importância do cuidado técnico, pois ele se faz necessário no atendimento às necessidades biológicas do sujeito, contudo, a sua ênfase em detrimento do expressivo, leva a um distanciamento da compreensão dos desejos do cliente. Logo, há de se encontrar um ponto de convergência em que o cuidado técnico e o expressivo sejam considerados e valorizados na sua justa medida, tendo em vista a integralidade do sujeito no seu contexto social, cultural, econômico, ético, estético, político, espiritual...

Oliveira $^{(10)}$ mostrou que essa interação entre o cuidado instrumental e o expressivo é possível. Ao realizar um estudo sobre a dialética do cuidado humano e o tecnológico com enfermeiras que atuam num centro de terapia intensiva na cidade do Rio de Janeiro, constatou que, mesmo diante de um cenário sofisticado, equipado com tecnologia de ponta, e que presta cuidados a uma clientela muitas vezes impedida de se expressar verbalmente, a Enfermagem pode e realiza, além do cuidado instrumental, o expressivo. Nesse contexto, a autora (2002, p. 45) ressalta que o cuidado técnico para ser considerado como cuidado humano é preciso que haja um encontro entre ambos. Segundo ela, "o cuidado que ocorre somente em sua vertente instrumental ou técnica não pode ser considerado humano, pois não imprime expressividade"(10:45).

A esse respeito,

[...] O cuidado de enfermagem antes de ser somente uma expressão técnica voltada eminentemente para objetivos médico-higiênicos é, principalmente, no plano do meu entendimento, um ato político que, como tal, não pode estar desvinculado do contexto institucional o qual se insere, do contexto sócio-cultural e do contexto individual do sujeito que o experimenta $[\ldots]^{(8: 73)}$.

Seguindo essa linha de raciocínio, apesar de 'Pedro' atribuir maior ênfase à vertente técnica ou instrumental do cuidado de enfermagem hospitalar no qual experimentou e qualificou como positivo, houve um encontro entre esta vertente do cuidado e a do tipo expressivo: Vejamos o diálogo que se segue:

De que maneira você participava desse cuidado? (Pesquisadoras)

Foi muito bom, com bastante atenção, tudo era conversado comigo [...] Sempre estávamos conversando, vejo que esta figura diz isso. Tudo que ia ser feito eu perguntava e a Enfermagem me respondia, inclusive a Enfermeira E. é muito atenciosa. (Pedro)

Para você, que tipo de diálogo se estabeleceu no espaço do cuidado de enfermagem? (Pesquisadoras)

Comigo, eu não tenho do que reclamar. Conversar resolve sempre muitos problemas na vida da gente, dentro e fora do hospital, em qualquer lugar. (Pedro)

Nesse ínterim, há de se ressaltar que, para alguns sujeitos do estudo, o cuidado expressivo, produtor de conforto e bem-estar é fundamental. Ele se expressa num sujeito que é singular e que, portanto, é diferente de outros sujeitos no plano de suas necessidades e de seus desejos; logo, o cuidado, por conseqüência, também é diferenciado e depende da singularidade de cada sujeito. No entanto, se, para alguns, ser 'bem cuidado' representa estar presente, ser atencioso e afetuoso; para outros, o cuidado técnico ou instrumental assume condição primordial, contudo, não dissociado do expressivo, como bem mostrou o discurso de 'Pedro'.

A fala de 'Jorge' seguiu orientação semelhante a de 'Pedro' no que pese a valorização da conversa na relação clienteequipe de enfermagem, ora enfatizando o cuidado expressivo, ora o cuidado técnico: [...] Eu participava como uma pessoa que 
precisava de cuidado. Na hora que elas cuidavam, elas me explicavam sempre [...] As explicações são sempre muito importantes. Um deslize da parte delas pode ser fatal [...].

A enunciação discursiva de 'Jorge' revela contentamento, gratidão e reconhecimento sobre o trabalho da equipe de enfermagem hospitalar que deve ser realizado, segundo ele, com competência e atenção. Complementando sua fala, 'Jorge' declarou: [...] a gente conversava muito [...] Na hora que estavam tratando de mim, me dando remédio, preparando para um exame ou quando eu precisava chamar para ver alguém que estava passando mal [...].

Já a fala de 'Margui' foi mais enfática quanto à importância da participação do cliente no cuidado de enfermagem hospitalar:

Achei essa figura (referindo-se a produção do Almanaque) bonita, bem colorida e com muita gente e todo o mundo participando. (Margui)

De que maneira você participava do cuidado? (Pesquisadora)

Como uma pessoa que estava ali para ser tratada e ficar boa, sempre que quis tive participação. (Margui)

No entanto, seu discurso também fez menção a algumas situações que, segundo ela, podem interferir na qualidade do cuidado. Vejamos:

Essa figura (produção do Almanaque) mostra um número muito pequeno de pessoas (referindo-se à equipe de enfermagem) para dar conta de tanta coisa... (Margui)

Que tipo de diálogo se estabeleceu no espaço do cuidado de enfermagem? (Pesquisadoras)

O diálogo é muito positivo, mas a enfermagem é sempre em número muito pequeno para a quantidade de pessoas que precisam de cuidado, que são dependentes delas. (Margui)

Por que você acha isso? (Pesquisadoras)

Porque elas (as enfermeiras) têm que ter muita atenção e aí não dá para conversar muito. Sempre conversávamos e todos tinham muita paciência comigo, mas, às vezes, só falavam o necessário para responder minhas perguntas. (Margui)

Por um lado, o discurso de satisfação expressa por 'Margui' ao fazer profissional da enfermagem e a relação interpessoal mantida com ela no cuidado, no nosso modo de apreender suas palavras, pode sugerir acomodação e ajustamento à realidade experimentada, revelando uma resignação diante do vivido no contexto hospitalar e serve de justificativa para o agir da equipe de enfermagem.

Por outro lado, sua fala alerta para uma situação freqüente na estrutura organizacional dos hospitais e na própria sistematização da profissão da enfermagem, caracterizada pela crise de identidade da enfermagem. Conforme sabemos, o quantitativo da categoria de enfermeiro nas instituições hospitalares, especialmente, as públicas, mormente se apresenta inferior ao explicitado nos cálculos das necessidades de desenvolvimento do trabalho desta categoria. Desta feita, na prática, suas atividades acabam por restringir-se, muitas vezes, àquelas de ordem gerencial no processo do trabalho. Ou seja, o número reduzido das enfermeiras nas instituições hospitalares passa a justificar a concentração de suas atribuições nas áreas de administração do cuidado e de liderança, gerando, um afastamento gradativo das enfermeiras no cuidado direto junto ao cliente, que passa a ser desempenhado pelas demais categorias de enfermagem ${ }^{(9)}$.

Por vários anos, tivemos a oportunidade de vivenciar esta situação como enfermeiras de um hospital público em que a educação à saúde como função precípua da enfermeira junto ao cliente vivendo com AIDS em diferentes cenários ou circunstâncias, era quase que anulada pela justificativa do número reduzido da categoria e a sobrecarga advinda do gerenciamento do serviço. A divisão técnica do trabalho na Enfermagem, traduz-se por uma prática parcelada em tarefas, procedimentos e responsabilidades diferentes, cabendo também esta execução parcelada a diferentes agentes ${ }^{(11)}$. Essa divisão técnica tem suas raízes na Inglaterra e na América do Norte, no século XIX e no início do século XX, respectivamente, quando da organização do espaço hospitalar como cenário de cura dos pacientes, em que os médicos passaram a ocupar um lugar de destaque. À Enfermagem, que sistematiza o seu saber e o fundamenta através dos princípios científicos, ao mesmo tempo em que também se desenvolve as técnicas médicas, coube a criação do ensino formal dos auxiliares de enfermagem. Essa iniciativa ocorreu para que à categoria dos auxiliares ficasse a responsabilidade da prestação dos cuidados de enfermagem possibilitando às enfermeiras a ocupação dos cargos de direção e o controle social do pessoal auxiliar.

Apesar das transformações na prática da enfermagem advindas do desenvolvimento das teorias de enfermagem a partir da década de 50 do século passado, no sentido da humanização da assistência e da busca da identidade profissional, o trabalho da enfermagem hospitalar ainda hoje sofre grande influência de sua inserção histórico-social expressas nas contradições de sua prática. Deste modo, conforme salientamos, uma significativa parcela do trabalho da enfermeira ainda se destina ao gerenciamento do cuidado, agravando ainda mais sua crise de identidade profissional.

Retomando o foco da discussão para a contribuição da conversa como cuidado integrador da enfermagem hospitalar, entendemos que esta "configura-se em um cuidado de enfermagem, na medida em que terá como função terapêutica minimizar a solidão sentida por ele (o cliente)"(8:213).

Neste ponto, ressaltamos que a conversa é um caminho para a interação pessoal, através da qual podemos identificar e intervir mais efetivamente nas solicitações de cuidado do cliente, conforme comentei anteriormente. Assim, a conversa, etapa essencial do diálogo, configura-se como um dos instrumentos do cuidado da enfermagem. No entanto, faz-se necessário que a equipe esteja atenta às mensagens emitidas pelo cliente. Pensamos que, conversar com o cliente envolve solidariedade e relação de ajuda-confiança para o enfrentamento das dificuldades advindas do processo de internação hospitalar, bem como àquelas que traz consigo do seu ciclo sócio-familiar.

Diante dessas considerações, o cliente, no ambiente hospitalar deve ser sempre reconhecido como um ser que pensa e age, que tem seus sentimentos aflorados, lembrando que é sensível, racional e espiritual, e que também, como todo ser humano em situações adversas e alheias à sua vontade, é passível de sentir medo, insegurança, solidão, dor e desprezo. É preciso que a equipe de enfermagem esteja atenta a essas manifestações, buscando entender o componente subjetivo da realidade do cliente hospitalizado, pois ele se questiona e quer questionar, tem o direito de expressar seu desejo, de elucidar suas dúvidas e anseios; e não somente de submeter-se às normas institucionais a ele impostas.

Nesse sentido, num exercício reflexivo sobre essas questões, ao nosso ver, de extrema relevância para o cuidado de enfermagem hospitalar, especialmente, em se tratando de um cliente que marca a diferença por ser portador de uma doença estigmatizante, como é o caso da AIDS, reforçamos que a comunicação proposta por Freire ${ }^{(7)}$ é a do diálogo e não a da extensão, em que apenas uma pessoa (a cuidadora) sabe e transmite este saber a outra (o cliente). A dialogicidade, portanto, permite ao cliente expressar suas idéias e opiniões. Ele estabelece com a equipe de enfermagem uma relação em que o diálogo implica em uma resposta humana positiva.

Portanto, os seres humanos "enquanto 'seres em situação', encontram-se submersos em condições espaçotemporais que influem neles e nas quais eles igualmente influem"(12:33). Assim, quanto mais o homem se posiciona, 
através de uma postura crítica e reflexiva sobre sua existência, maiores condições terá de atuar sobre ela. Sustentamos que, no espaço intersubjetivo do cuidado de enfermagem hospitalar, isso é possível pelo encontro dialógico em que o cliente e o cuidador marcam posição enquanto sujeitos em relação, por meio da integração, pela ação e na ação.

Em síntese, a participação pelo diálogo conduz o cliente a falar, a fazer reivindicações, a expressar suas necessidades e desejos de cuidado. Ou seja, o cuidado participativo é humanizante. E no que pese o seu caráter relacional, lembramos que um dos pressupostos da teoria de Watson diz "que o cuidado pode ser praticado e demonstrado apenas interpessoalmente"(13:254).

\section{Referências}

1. Watson J. The theory of human caring: retrospective and prospective Nursing Science Quarterly, Baltimore (MD) 1997;10(1):49-52.

2. Freire P. Pedagogia do oprimido. $31^{\mathrm{a}}$ ed. Rio de Janeiro: Imago; 2001. $184 \mathrm{p}$.

3. Freire P. Pedagogia da autonomia. Saberes necessários à prática educativa. 6a ed. São Paulo: Paz e Terra; 1998. 165 p. (Leitura).

4. Orlandi EP. Discurso \& texto e circulação dos sentidos. Campinas (SP): Pontes; 2001. $192 \mathrm{p}$.

5. Orlandi EP. A linguagem e seu funcionamento: as formas do discurso. $4^{a}$ ed. Campinas (SP): São Paulo: Pontes; 1996. 135 p
6. Freitas MTA. Nos textos de Bakhtin e Vygotsky: um encontro possível. In: Brait B, organizador. Bakhtin, dialogismo e construção do sentido. Campinas (SP): Editora da UNICAMP; 1997. 385 p. (Repertórios).

7. Freire P. Extensão ou comunicação? $11^{a}$ ed. São Paulo: Paz e Terra; 2001. 93 p. (O mundo hoje; 24).

8. Ferreira MA. O corpo no cuidado de enfermagem: representações de clientes hospitalizados [tese de Doutorado em Enfermagem]. Rio de Janeiro: Escola de Enfermagem Anna Nery, Universidade Federal do Rio de Janeiro; 1999. $255 \mathrm{f}$.

9. Waldow VR. Cuidado humano: o resgate necessário. $2^{\mathrm{a}}$ ed. Porto Alegre (RS): Sagra Luzzatto;1999. 202 p. il.

10. Oliveira RS. A dialética do cuidado: o humano e o tecnológico em um centro de terapia intensiva [dissertação de Mestrado em Enfermagem]. Rio de Janeiro: Escola de Enfermagem Anna Nery, Universidade Federal do Rio de Janeiro; 2002. $129 \mathrm{f}$.

11. Almeida MCP, Rocha JSY. O saber de enfermagem e sua dimensão prática. $2^{a}$ ed. São Paulo: Cortez; 1989. 128p. il.

12. Freire P. Conscientização: teoria e prática da libertação. São Paulo: Moraes; 1980. 102 p.

13. Talento B. Jean Watson. In: George JB, editora. Teorias de enfermagem: os fundamentos à prática profissional [tradução de Ana Maria Vasconcellos Thorell]. $4^{\mathrm{a}}$ ed. Porto Alegre (RS): Artes Médicas Sul; 2000. 375 p. p.254-65.

Data de recebimento: 17/02/2003

Data de aprovação: 20/08/2003 